\title{
Birth Control and Family Planning Using Intrauterine Devices (IUDs)
}

\author{
Iliescu Dominic Gabriel, Ștefania Tudorache, \\ Simona Vlădăreanu, Nuți Daniela Oprescu, \\ Maria Cezara Mureșan, \\ Roxana Cristina Drăgușin and Iuliana Ceaușu \\ Additional information is available at the end of the chapter
}

http://dx.doi.org/10.5772/intechopen.72242

\begin{abstract}
Intrauterine devices (IUDs) represent one of the most important methods used for contraception. The methods vary in terms of efficiency, acceptability, costs, and potential complications. Early methods have been improved, and ultrasound (US) evaluation has become an important tool to diagnose the clear majority of IUDs complications. This chapter presents a comprehensive and up-to-date status regarding the use of intrauterine devices (IUDs) for birth control and family planning. The topics discussed in the manuscript will involve the current knowledge on the history, types, mechanisms, health benefits, and risks. More, the present paper presents the medical techniques for inserting and removing a IUD, and the role of US to confirm proper IUD placement. Also, this chapter offers practical guidance in managing problems of continuing users and discusses the clinical circumstances that require reconsideration of the contraception methods.
\end{abstract}

Keywords: intrauterine device, copper intrauterine device, hormonal intrauterine device, contraception, family planning, ultrasound

\section{Introduction}

Intrauterine devices (IUDs) represent long-lasting reversible birth control method [1] with the greatest satisfaction among users [2]. However, this contraceptive use generated much heated discussion and debates, with exhaustive studies that are presented in the present chapter. 


\section{History of IUDs}

Intrauterine contraception with various devices seems to have a long history, from the ancient Arabs who placed round smooth stones in the camels' uteri to prevent conception during long journeys. In the late nineteenth century, intracervical devices have been used to prevent pregnancy or to induce abortion [3]. Still, the first medical communication on medical IUD was published in Germany, at the beginning of the twentieth century by Richter [4], who reported the results of intrauterine insertion of a metallic ring with catgut tied around it. In the 1920s, Ernest Graefenberg attached a silver wire to the ring for Roentgen visualization, but silver rings were rapidly abandoned as they led to gingival argyrosis. An alloy of copper, nickel, and zinc was used instead [5]. In 1959, the first paper was published who condemned the IUDs as dangerous because of the ineffectiveness, risk of infection, and carcinogenic potential [5]. The modern IUDs evolved from 1960 with a T-shaped product that configured better to the natural shape of the uterus [6]. By the mid-1960s, IUDs became a widely used method with fewer potential cardiovascular risks when compared to oral contraceptives [7]. In 1970, nearly 10\% of women were using the Dalkon Shield IUD as a contraceptive method. Since then, the use of IUDs dropped because of the severe septic cases reported, along with the increased risk of pelvic inflammatory disease (PID) and infertility [8]. IUDs were even withdrawn from the US market between 1986 and 1988.

Since the introduction of the levonorgestrel $52 \mathrm{mg}$ IUD in 2001, this intervention achieved a new, therapeutic, dimension-because of significant benefits in treating heavy menstrual bleeding and dysmenorrhea [7].

Today, IUDs are an important component of family planning, as they are used by one in 10 women in the USA and 9-24\% of all contraceptives in European countries [9]. The highest rates of IUD use are recorded in Asia: $40 \%$ of women in China, 50\% in Korea, and 56\% in Uzbekistan [10], while the lowest rates are recorded in Africa. The trend of contraceptive method is declining as the use of injectable products is increasing [11]. From the beginning, the gynecologists were preferred for a safe insertion of the IUD, instead of general practitioners [3].

\section{Types of IUDs: copper and hormonal}

The two main types of IUDs are the copper non-hormonal device and the hormonal device.

There are a few types of copper devices as well. The most frequent copper device series are the T380 devices that also consist of the original T380 A, the T380 Ag available in Finland, and the T380S available in Canada and UK [12]. This IUD has a small plastic "T" frame with a stem wrapped with copper wire and also copper collars on the two arms of the frame, of about $380 \mathrm{~mm}^{2}$ of copper. T380A has been approved around the world for up to 10 years [13], with no uterine perforation reported, but a high rate of medical removal due to bleeding, pain, and pelvic infection [12]. 
Other types of copper IUDs include the Multiload series of devices that consists of ML250 for a 3 years' use and the $M L 375$ with more copper to enhance a longer use, up to 5 years. The device has additional plastic fins on the lateral, and curved arms to avoid spontaneous expulsion [12].

The GyneFix device has been introduced in 1997 as a frameless copper-bearing device designed especially for nulliparous women. However, it associates an increased risk of expulsion in the first 3 months. Both GyneFix and T380A are reported to have high efficiency in women contraception [14].

Besides pure copper devices, there is also a gold IUD called Eurogine Gold T, Goldlily, or GoldringMedusa, with a gold core that prevents the copper from fragmenting or corroding [15].

Silver was also being added on a copper device, to reduce fragmentation, and to prolong the lifespan of the device. The production of the initial NovaT200 was ceased, because of poorer performance and NovaT 380 was developed [12].

To reduce side effects of IUDs such as bleeding, pain, and expulsion, Flexi-T300 was introduced, with a smaller and more flexible frame and thinner side arms that are bent back on themselves. Flexi-T300 is also preferred for emergency contraception, as it is cheap and easily inserted and removed [12].

Since 1976, medicated or hormonal IUDs were developed. Mirena was produced in 2001 as a hormonal IUD releasing $52 \mathrm{mg}$ of levonorgestrel during a 5 years' period of approved use [7]. Mirena releases approximately $20 \mu \mathrm{g}$ of levonorgestrel daily in the first few weeks with a decrease to $18 \mu \mathrm{g} /$ day by the end of 1 year and $10 \mu \mathrm{g} /$ day after 5 years [16]. Other hormonal IUDs, as Skyla or Jaydess, have a shorter period of use (3 years) because of the lower levonorgestrel content $(13.5 \mathrm{mg})$, that is released $14 \mu \mathrm{g}$ daily after the first few weeks and with a rapid decrease to $10 \mu \mathrm{g} /$ day by 2 months and $5 \mu \mathrm{g} /$ day by the end of 3 years [17]. Besides contraception, the hormonal IUDs reduce the blood flow with amenorrhea in about $20 \%$ of cases within 1 year [18]. FibroPlant is a frameless levonorgestrel-releasing IUD with a nonresorbable thread through the center and with similar effects on uterine-bleeding patterns as Mirena [12].

Other IUDs include the copper indomethacin type, available in China, with a silicone elastomer beads containing $25 \mathrm{mg}$ of indomethacin that does not interfere with the copper release and reduces the menstrual cramping [12].

In Austria and Israel, a copper intrauterine ball is available, which once inserted takes the shape of a sphere. The rationale of the ball shape is to reduce the irritating effect of classic copper IUD. It is also easy to insert with no uterine perforation reported and highly accepted by patients [19].

New IUDs, such as flexible VeraCept-that utilize a low-dose copper configuration of $175 \mathrm{~mm}^{2}$ surface area on a shape memory Nitinol frame-need clinical trials for validation of efficacy and tolerability [20] (Figures 1 and 2). 


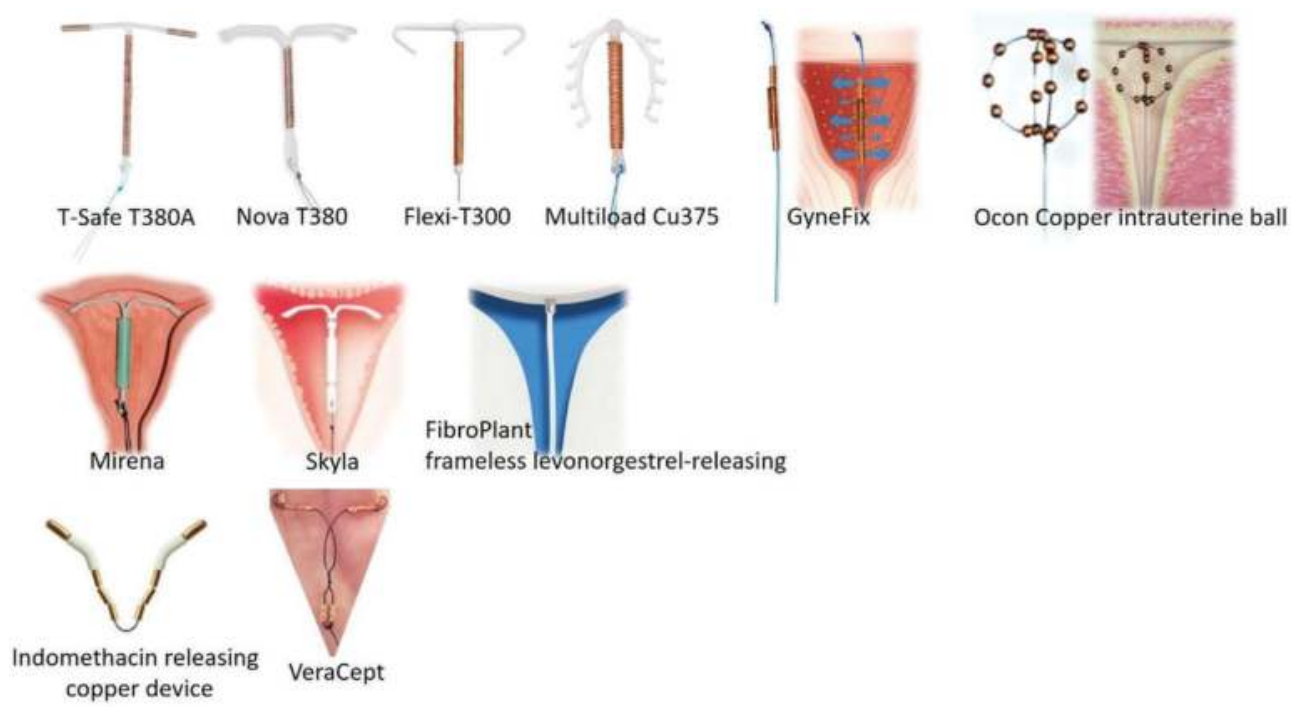

Figure 1. Various types of IUD. Copper devices presented in the upper row, from left to right: T Safe Cu380A ${ }^{\oplus}$, Nova $\mathrm{T}_{380^{\oplus}}$, Flexi-T300 ${ }^{\circledR}$, Multiload Cu375 ${ }^{\oplus}$, GyneFix ${ }^{\oplus}$, Ocon ${ }^{\circledR}$ Cooper intrauterine ball. In the middle row - hormonal IUDs: Mirena ${ }^{\circledR}$, Skyla ${ }^{\circledR}$, FibroPlant ${ }^{\circledR}$ frameless levonorgestrel-releasing device. In the lower row, other IUD types are presented, as the indomethacin-releasing cooper device $\mathrm{AiMu}{ }^{\circledR}$ and the flexible, low copper dose VeraCept ${ }^{\circledR}$.

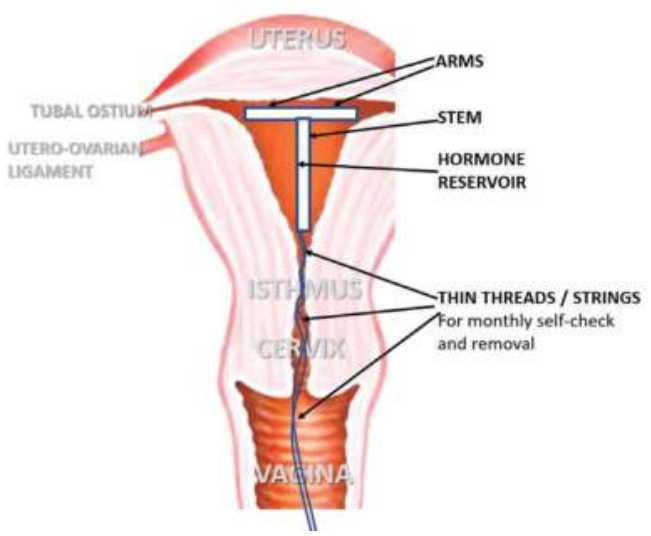

Figure 2. General structure with stems, arms, and strings of the IUD. Normal location after proper IUD insertion in the middle of the endometrial cavity with no extension in the myometrium, both arms spread toward the uterine horns and the inferior part of the vertical body stem just above the isthmus.

\section{IUDs mechanism of action}

Both copper and hormonal IUDs involve multiple mechanisms that provide contraceptive protection. The major described effect is represented by the induction of a local inflammatory reaction in the 
endometrium. Therefore, the endometrial and myometrial function is disturbed by cellular and humoral immune-inflammatory reaction. Intrauterine foreign bodies are known to interfere with reproduction in all species [21]. Other mechanisms of action for copper IUDs are related to copper ions' effect on the sperm motility and viability and also to changes of the cervical mucus [7]. However, recent studies demonstrated no significant increase in inflammatory reaction, so the effect of copper on the sperm or oocyte remains as the main mechanism of action [22]. The mechanism of inhibiting fertilization or sperm viability impairment may be responsible for the high efficacy of copper IUDs as emergency contraception [23]. The reported failure rate for copper IUD placement for emergency contraception within 5 days of intercourse or ovulation is less than $1 \%$, significantly more effective than any hormonal emergency contraceptive [24, 25]. Even if copper IUDs do not usually influence the menstrual frequency or quantity, 10-13\% of women have their IUD removed in the first year due to increase of menstrual flow and cramping-type abdominal pain [26].

Besides the foreign body reaction, another mechanism of the hormonal IUD is represented by the release of small amount of progestin hormones, respectively, levonorgestrel. The hormonal effects induce an unfriendly and even fatal environment to sperm inside the uterus, with inhibition of capacitation, penetration, and survival [27]. Hormonal IUDs interfere with sperm motility by thickening cervical mucus, thus preventing the sperm to travel up into the uterus [28], while copper IUDs rather impair the sperm viability, with various effects as head-tail disruption [29]. A thinner endometrium develops under the progesterone influence and egg implantation is affected. Also, menstrual blood flow is reduced, thus hormonal IUDs are frequently used to treat menorrhagia [30].

We underline that IUDs, whether hormonal or non-hormonal, do not provide protection against sexually transmitted diseases. Still, the historical association with pelvic inflammatory disease (PID) and tubal infertility is considered false [31, 32].

The indomethacin-releasing copper IUD contains a nonsteroidal anti-inflammatory agent, indomethacin, that do not interfere with copper ions [33,34], aimed to reduce the menstrual blood flow and cramping that are frequently related by IUDs users [33] (Table 1).

\begin{tabular}{lll}
\hline Mechanisms of action & \multicolumn{2}{c}{ Type of intrauterine device } \\
\cline { 2 - 2 } & Copper IUD & Hormonal levonorgestrel IUD \\
\hline Effects on sperm & + & + \\
Foreign body reaction with toxic changes to sperm & + \\
Copper ions spermicidal or cytotoxic & + \\
Thickened cervical mucus affecting sperm motility & + \\
Effects on fertilization & + \\
$\begin{array}{l}\text { Decreased number of fertilized ova in fallopian tubes } \\
\text { Effects on the endometrium }\end{array}$ & + \\
Immune-inflammatory reaction with increased leukocytes & + \\
Altered cytotoxic cytokine and integrin profile & + \\
Endometrial atrophy, decreased thickness, and secretions & + \\
\hline
\end{tabular}

Table 1. Mechanisms of action of the main types of IUDs. Modified, Schulman et al. [35]. 


\section{Adverse and side effects, health benefits, and risks of IUDs}

Generally, all IUDs are well tolerated with high rates of continuation in all reversible contraception types [36]. All IUD types present potential side effects: uterus perforation and malposition, especially during the inserting technique; embedment and expulsion, as it is a foreign body, and menstrual pattern alterations (Figure 3). All patients should be counseled regarding the possibility of IUD expulsion as this is the most common complication following IUD insertion [37].

The expulsion rate is reported to be similar for copper and hormonal IUDs, as well as in nulliparous versus parous women, approximately $5 \%$ [38].

Uterine perforation is rare and surgical intervention is recommended if this occurs, but this is not an emergency in asymptomatic cases [39]. In these patients, a new IUD placement should be considered after at least 4-6 weeks time interval needed for uterine wall healing [40].

A rarely reported complication is the embedment within the endometrium. This should be suspected at the ultrasound (US) follow-up, or clinically, if no IUD strings are visualized at the cervical os or there is difficulty with removal [41].

Copper IUDs can cause menstrual pattern alterations, especially irregular, heavy and painful bleeding, and intermenstrual spotting or bleeding as well throughout use [42, 43].

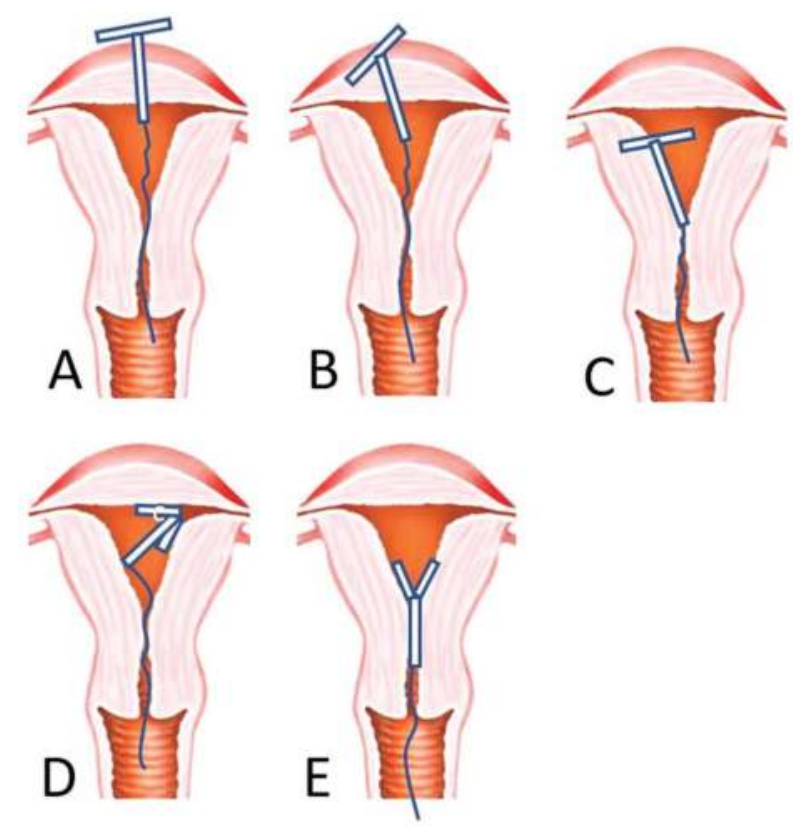

Figure 3. IUDs complications. (A): complete uterine perforation; (B): partial uterine perforation; (C): partial embedment into myometrium; (D): malposition; (E): expulsion after insertion. 
Regarding the hormonal IUDs side effects, they are similar to other progestin-based contraceptives such as headaches, nausea, hair loss, breast tenderness, depression, decreased libido, and ovarian cysts [44, 45]. Also, vulvovaginitis and abdominal or pelvic pain may be experienced by users of hormonal IUDs [44, 45]. On the contrary to copper IUDs, the hormonal IUDs usually cause amenorrhea and oligomenorrhea after 2 years of use [42, 44].

The contraindications/health risks for IUD use are current pregnancy or gestational trophoblastic disease, cervico-vaginitis or acute pelvic inflammatory disease, including pelvic tuberculosis, puerperal sepsis and recent septic abortion, uterine (cervical or endometrial) cancer, unexplained vaginal bleeding, and malformed uterine cavity. Other systemic contraindications include copper allergy, immunodeficiency disorders, immunosuppressive therapy, Wilson's disease, acute liver disease or liver carcinoma and breast carcinoma-especially for hormonal IUD, multiple sexual partners for the patient or her partner.

The major health benefit of IUD is represented by the efficacy in contraception similar or better than female sterilization. The cooper IUD failure rate is reported to be $0.8 \%$ at 1 year, while a failure rate for hormonal IUD is reported to be $0.1 \%$ at 1 year $[46,47]$. Of great importance is that this efficacy is not influenced by or related to patient age, multiple medications, or medical comorbidities and does not require patient compliance [48]. IUDs can be safely placed immediately after abortion or 6 weeks postpartum with high contraceptive benefits [49]. Copper IUD is recommended as the most effective option for emergency contraception [50].

Another IUD benefit is the fact that it can be used as an adjunctive treatment modality for intrauterine adhesions. Several studies have shown that IUD can be beneficial in patients with intrauterine adhesions or Asherman's syndrome, especially when combined with other ancillary treatments [51].

Other noncontraceptive benefits of IUDs include the treatment of menorrhagia, anemia, dysmenorrhea and pelvic pain associated to endometriosis, and endometrial protection during hormone replacement [48]. Since 2009, when Food and Drug Administration (FDA) approved the hormonal IUD as treatment for heavy menstrual bleeding, hormonal IUDs became the most cost-effective alternative to hysterectomy/surgery for the respective patients, with improved hemoglobin concentration [52]. Studies report a decrease of the menstrual blood loss that varies between 74 and $97 \%$ at 12 months of use [53, 54]. First, an initial irregular bleeding pattern is noted by most users, but over time the menstrual blood loss is improved. In contrast with copper IUD, the hormonal IUD can also decrease dysmenorrhea [55].

In $30 \%$ of patient with deep endometriosis or adenomyosis, an improved control of chronic pelvic pain and dyspareunia is noted after at least 6 months of hormonal IUD use [56, 57].

As the main effect of hormonal IUDs is to decrease the local endometrial response to estrogen, several studies have suggested that this may lead to primary protection from endometrial cancer [58]. Hormonal IUDs can also be used as a component of combined hormone therapy in menopausal women [52].

The use of IUD contraception is considered a health benefit in special groups such as women with comorbidities, in postpartum, postabortion and lactating women, patients with prior 
thromboembolic events, bleeding diathesis, or under anticoagulation. Also, IUD contraception can be a preferable option in women with uterine fibroids after uterine artery embolization, endometrial ablation, or magnetic resonance-guided focused ultrasound.

However, the IUD does not protect from sexually transmitted diseases; therefore, caution must be considered when selecting IUD users.

\section{Correcting misunderstandings, myths, and barriers}

\subsection{IUD and PID}

Since the introduction of IUDs, scientists manifested a concern that this contraception method may cause or facilitate gynecologic infection. In fact, the relationship between IUD and PID has a long and controversial history dating since 1940 [59]. Moreover, in the 1970s, the reputation of IUD was tarnished in many countries, as the use of a Dalkon Shield IUD was linked to several cases of potentially fatal pelvic sepsis [60]. Today, although there is common reserve regarding the PID incidence in the IUD users' population, valuable research has shown that the risk of PID is no greater with IUD use than the general population [61]. WHO admits a risk of six times greater of PID in the first 20 days after the insertion of IUD [61]. One randomized trial found that the hormonal IUD might provide some protection against PID when compared to the group of copper IUD users and the group of IUD non-users [62]. Due to this risk, prophylactic antibiotics were proposed before IUD insertion, especially doxycycline and/or azithromycin. Multiple large, randomized control studies have demonstrated that the prophylactic antibiotic has no significant beneficial role in reducing the risk of PID before IUD insertion [63].

\subsection{IUD and tubal infertility}

Tubal infertility was thought to be a consequence of IUD use. Specific research has been conducted and found that the past use of copper IUD did not increase the risk of tubal infertility [59]. Chlamydia infection is the primary cause of PID and tubal infertility in women who use or do not use IUD [31]. A cervix already infected with Chlamydia was considered to be a risk factor for placing an IUD, but proved to have no association with PID on later development [64].

\subsection{IUD and the risk of ectopic pregnancy}

In the past, IUD was perceived as a high risk factor for ectopic pregnancies (EPs). Actually, a pregnancy with an IUD in situ has an increased risk of being an EP, but the absolute risk of any pregnancy is extremely low in the group of IUD users, much lower than in the group of women with no contraception method $[65,66]$. Another important aspect to highlight is that a history of previous EP does not represent a contraindication for IUD insertion [67].

\subsection{IUD in nulliparous women}

Adolescents and nulliparous women represent a special group that was considered, in the past, not eligible for IUD contraception. Approximately half of adolescents have never heard 
of IUD contraception [68]. What is more, approximately one-third to one-half of health providers do not offer IUD contraception method to nulliparous women due to several myths and misconceptions [69]. Nowadays, there is sufficient evidence to support the use of IUDs in the nulliparous women as a suitable contraception method, regardless of all false myths and misconceptions including high risk of PID, tubal infertility, EP, gynecological neoplasia, difficulties of the insertion technique, and IUD expulsion [70].

\subsection{IUD and gynecological neoplasia}

There is a lack of awareness and understanding of IUD contraception by women worldwide, possibly due to lack of medical education and proper information. A frequent misconception of IUD use is that it increases the risk of genital cancer. Mandatory screening for cervical cancer is a requirement of many guidelines before IUD insertion. In fact, several epidemiological studies suggested that IUDs might protect against cervical carcinogenesis [71]. The role of hormonal IUD as a protective factor against endometrial hyperplasia is well known [58]. Accurate information regarding the use of hormonal IUD must underline the risk of ovarian cysts, but not ovarian cancer.

\subsection{IUD and female sexual dysfunction}

Female sexual dysfunction was thought to be determined by IUD but in fact has a multifactorial etiology and studies found no difference between IUD users or non-users [72].

\section{The technique of inserting and removing IUDs}

IUD represents the choice method of contraception for many women as its effects are reversible after removal.

The insertion technique is easy and well tolerated by selected female patients after taking into consideration the contraindications, as well as the health benefits for women with anemia, menorrhagia, or dysmenorrhea [73]. First, it is advisable to have a documentation of a negative pregnancy test as a precaution. Also, exclusion of a possible Chlamydia or gonorrhea is advisable before an IUD is inserted [74]. The insertion can be performed at any time during the menstrual cycle [42]. In the past, the technique was preferred to be done during menses to exclude pregnancy, but this is associated with a higher risk of expulsion. Several studies found that the pain during the insertion is lower during the sixth and the tenth days of the menstrual cycle [26]. Regarding the insertion of a hormonal IUD, the appropriate timing is considered to be within the first 5 days of menstrual bleeding or immediately after childbirth, abortion, or switching from an alternative contraceptive method [42, 75]. Backup contraception is recommended for a period of 7 days after the hormonal IUD insertion and is not needed after the copper IUD insertion [48]. In cases of emergency contraception, the insertion of the copper IUD can be done within the 5 days of the unprotected intercourse to prevent pregnancy [25]. The use of a hormonal IUD has not been yet studied and so it is not recommended for emergency contraception. The removal of both the copper IUD and the hormonal IUD can be performed anytime preferably during the menstrual cycle. As mentioned before, antibiotic prophylaxis is not needed before IUD insertion 
or removal, even in patients at risk for endocarditis [76]. The insertion procedure is usually done by a trained provider in the office, and only in special circumstances, such as mentally limited patients and nulliparous young women, it can be done under sedation. The physician must discuss all risks and benefits of IUD with the patient and must obtain an informed consent. The use of misoprostol before IUD insertion to allow an easier procedure was proposed in 2007 [77]. However, more recent researches found no benefit but increased side effects with misoprostol, and no recommendation has been yet made [78, 79]. On the other hand, the use of a nonsteroidal anti-inflammatory drug, respectively, $600-800 \mathrm{mg}$ of ibuprofen $1 \mathrm{~h}$ before the procedure can alleviate discomfort [80]. Also, the physician must educate the patient in locating the IUD threads after each menstruation and consulting earlier if incapacity to locate [80]. IUD insertion is similar for copper IUD and for hormonal IUD. The preparation before IUD insertion must include the determination of uterus position. This can be done by a bimanual examination or by an ultrasound examination. All proper equipment must be sterile and assembled before the procedure. The cervix and vagina must be cleansed with antiseptic solution. A speculum is used to visualize the cervix and a tenculum to stabilize the cervix. Local anesthesia is preferred with lidocaine gel in the cervical canal, or a paracervical block. The uterine depth must be verified using a hysterometer and the IUD is inserted as shown in the accompanying written material of any IUD. After proper insertion, the threads should be cut to a length of $3 \mathrm{~cm}$. A post-procedure ultrasound should be performed to verify the IUD position [81]. The removal procedure should be considered anytime on patient request. If any contraindication appears or adverse effects persist, IUD can be easily removed by grasping the threads at the external os. Special conditions include impossibility to remove the IUD with a simple traction; deeply embedment IUD should be suspected and in such cases, hysteroscopy is mandatory. Cervical screening is performed the same as in IUD non-users. Colposcopy is performed the same, but excisional procedure for cervical dysplasia must be performed after IUD removal [81].

\section{The role of ultrasound in IUD users}

US evaluation of the pelvis, especially transvaginally, has become an important part of the gynecological care and is essential for the assessment of IUD position after insertion [81]. Moreover, the lack of a pelvic US examination before IUD insertion may predispose to malposition or serious complications such as perforation [82]. US assessment is cheap, easy to learn, perform and interpret, efficient, and without side effects [81]. A correct positioned IUD is visualized in the middle of the endometrial cavity with no extension in the myometrium, with both arms spread toward the uterine horns and the inferior part of the vertical body of the IUD just above the isthmic portion of the uterus [83] (Figure 4). The two-dimensional technique has some limits in the evaluation of the IUD position, as the most important plane for this purpose, the coronal plane, usually cannot be imagined. Three-dimensional (3D) assessment is also helpful to identify hormonal IUD, because of the lack of echogenicity (Figure 4B), unlike copper IUD that are easily identified due to its high echogenity.

About $10 \%$ of IUDs are malpositioned and so the efficacy in contraception is significantly decreased. More than half of the patients with a malpositioned IUD are asymptomatic. Still, 


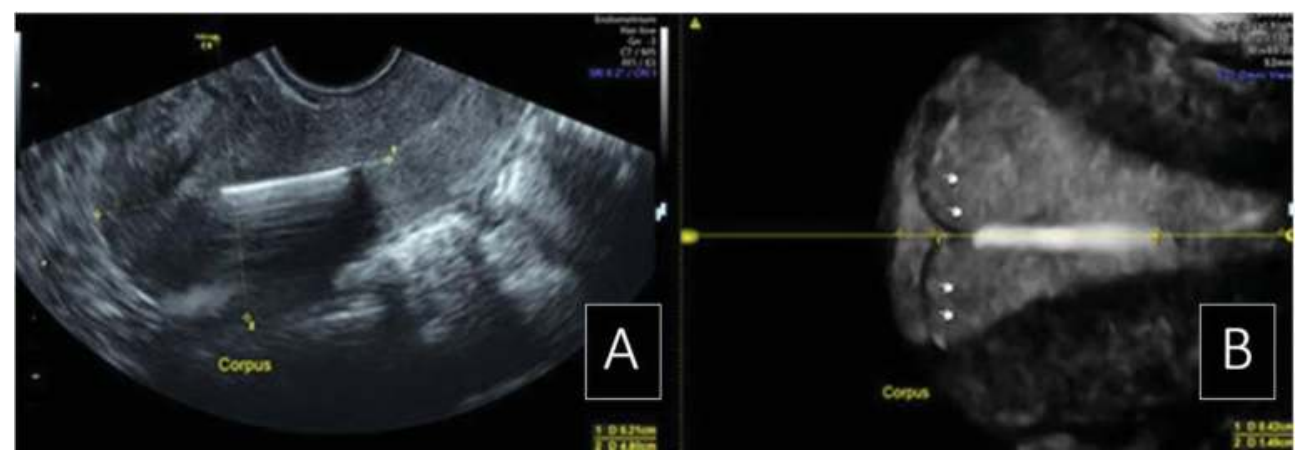

Figure 4. Ultrasound image of hormonal IUD. (A) 2D image; (B) 3D rendering, with reconstruction of the coronal plane.

there are no general guidelines for a routine transvaginally US verification after IUD insertion [84]. The 3D US technique has the advantage to allow subsequent reconstruction of the coronal plane [83]. This approach provides a correct diagnosis regarding the malposition, expulsion, displacement, embedment, or perforation (Figure 5). It can also detect more specifically uncommon complications such as fragmentation and calcification [81]. So, 3D has become crucial as it is more sensitive in assessing symptomatic IUD users, but also for routine evaluation. However, familiarity with the transvaginal 2D/3D US techniques is essential.
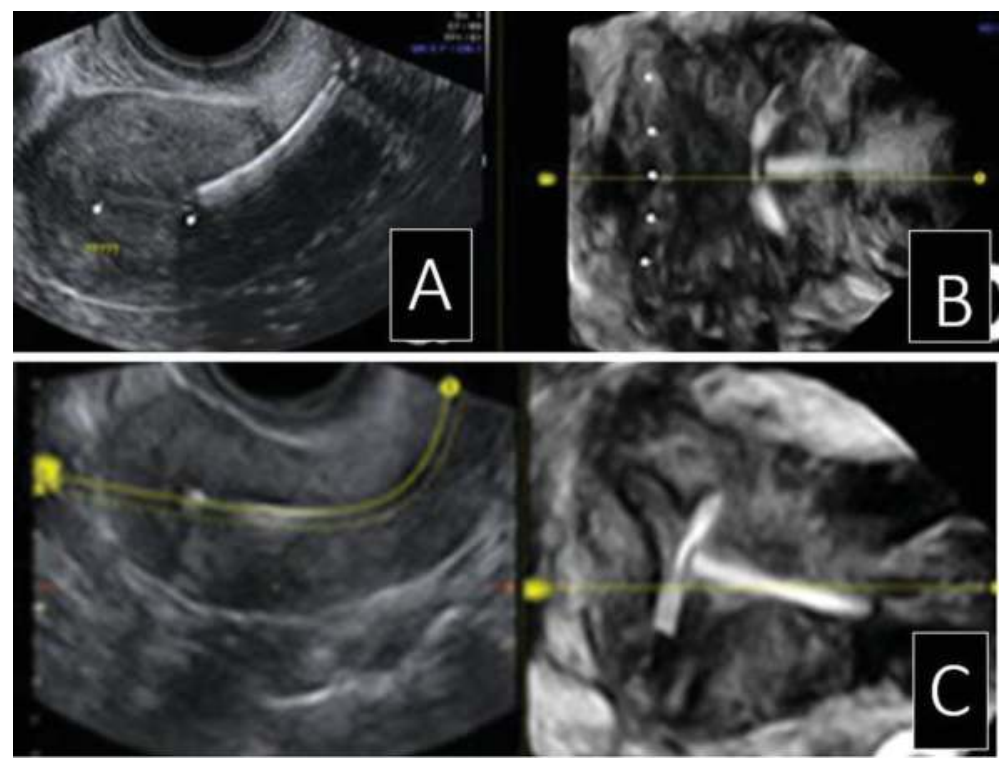

Figure 5. Ultrasound image of a malpositioned copper IUD. (A) 2D image; (B) 3D rendering of the coronal plane showing copper IUD displacement; (C) 3D rendering showing copper IUD partial embedment into myometrium. 


\section{Management of problems in continuing users}

Patient satisfaction and acceptability are extremely important regardless of their contraceptive method. After a proper counseling regarding the risks and the benefits, women choose the appropriate most effective contraception option to prevent an undesired pregnancy. The continuation rates for copper IUD are reported to be as high as $84 \%$ at 12 months and $85 \%$ for hormonal IUD [85]. Overall, the satisfaction rates of women users of IUDs are the highest between all other contraceptive methods [86]. In terms of IUDs advantages, the most frequently reported reasons are the ease of use, efficacy, and reliability, but also reduction of the menstrual flows when using a hormonal IUD [40].

Pelvic pain is the most frequent side effect of any IUDs. Approximately $27 \%$ of copper IUD users and $34 \%$ of hormonal IUD users have their IUD removed prior to 6 months because of continuing cramping [87]. The post-insertion pain can be managed with $400 \mathrm{mg}$ of ibuprofen/325-650 mg of aspirin/325-1000 mg of paracetamol/200 mg of naproxen. The postinsertion recommendations forbid tampons, vaginal douching, and sex for $24 \mathrm{~h}$ [48].

Another reason for discontinuation is represented by irregular bleeding patterns especially for hormonal IUD users. With the copper IUDs, most women continue to have regular monthly periods and bleeding may get heavier [48]. In such cases, tranexamic acid can be required for a short-term relief, but unfortunately, it is not available in many countries. Another option may be nonsteroidal anti-inflammatory drugs, such as indomethacin, but not aspirin. Anemia may be a serious side effect of using copper IUD, so patients must receive iron tablets for the anemia prevention or indication to a specific diet rich in foods containing iron. Amenorrhea is a common side effect when using hormonal IUD. Even if irregular bleeding may bother the user, the menstrual flow is overall decreased [88]. In adolescents, a 7\% rate of discontinuation has been reported within the first year, independent to the IUD type, due to abnormal bleeding [89].

Most cases of discontinuation can be prevented by an accurate medical informed discussion between the user and the health provider prior to IUD insertion. Both types of IUD should be taken into consideration and the best decision must consider the benefits, but also all adverse effects. The most important disadvantage of IUD use is the fact that it does not offer protection from sexually transmitted diseases and condom should be used for this purpose. In rare cases, the male partner can feel the IUD retrieval strings or stem during intercourse and this may bother him. Strings can be cut shorter or in some cases the IUD can be removed and a new one inserted. Lack of medical education seems to be the main cause for the reduced uptake and continuation rates for intrauterine contraception among female patients [90].

\section{When to switch to other contraception methods}

Other contraception methods should be considered if menstrual bleeding is increased when using copper IUDs or if irregular bleeding induced by using the hormonal IUDs becomes a disturbance in the female patient's routine.

PID or EP represents a cause for severe pain in the lower abdomen. However, PID does not represent an indication to remove the IUD before starting antibiotic treatment. If EP is diagnosed, 
IUD must be removed and proper specific treatment should be initiated. IUD should be removed also in intrauterine pregnancy cases. If the woman wants to terminate the pregnancy, the removal procedure is done before the evacuation of the uterus. If the woman wants to continue the pregnancy, early removal of the IUD reduces the risk of preterm delivery or miscarriage.

During the insertion procedure, perforation may be suspected. In such situations, immediate removal of the IUD is recommended along continuous monitoring of the patient's vital signs. If perforation is suspected after 6 weeks of insertion or later, then the IUD should be removed by an experienced clinician and other contraception method should be considered.

If the IUD is partially expelled, it must be removed and insertion of a new one should be decided with the patient after careful counseling. If the IUD is completely expelled, then other contraceptive methods are advisable.

Male discomfort during intercourse is a rare cause for switching to other contraception methods.

\section{New alternative to IUD}

A series of medical conditions, due to high maternal mortality rates approaching $50 \%$, represent an imperative indication for the most reliable methods of contraception in women. Essure was introduced in 2002 as a new sterilization method for women who do not desire to preserve fertility or for those who have significant medical contraindications. Essure is composed of two intra-tubal stents that must be inserted into the proximal section of the fallopian tube. This procedure is done hysteroscopically using only oral analgesia or sedation [91]. The contraceptive effect is installed in 3 months after insertion due to mechanical obstruction and inflammation causing fibrosis [92]. Thus, an additional form of contraception must be used in the meantime other than IUD. The main advantages of Essure are represented by the fact that Essure is non-incisional, permanent birth control device [93]. The insertion procedure is ideally performed in the proliferative phase when the tubal ostia can be easily visualized and cannulated. Tubal stenosis and tubal spasm can determine the failure of placement, but also poor visualization [94]. The procedure success rate varies from 85 to $98 \%$ [95]. When inserted, there is a risk of vaso-vagal attacks of $1.85 \%$ [96]. The Essure contraindications are the uncertainty regarding ending fertility, suspected pregnancy, active or recent PID, uterine anomalies, less than a 6-week interval after delivery or miscarriage, patient unwilling to use other contraceptive methods for the first 3 months, prior tubal ligation, and current immunosuppressive therapy [97]. After 3 months post-insertion, an imaging method to verify the position of the Essure is recommended. Several studies have been done in order to establish the best imaging method between hysterosalpingogram (HSG), X-ray, or hysterosalpingocontrast sonography. Still, all studies underline the importance of trained staff in assessing the appropriate Essure placement [93] (Figure 6). As complications, mild pain has been reported in most cases $-80 \%$ of patients, while severe pain may be encountered in $17 \%$ [98]. Also, minor symptoms like cramping, nausea, and light bleeding or spotting can also occur in the first week [3]. Severe complications like tubal perforation and expulsion are rare. Essure is compatible with $1.5 \mathrm{~T}$ of magnetic resonance imaging (MRI), but special caution is indicated in $3 \mathrm{~T}$ MRI and with some techniques of endometrial ablation. In terms of efficacity, Essure has a $99.74 \%$ successful rate in permanent contraception after 5 years [97]. The minimal risk of 


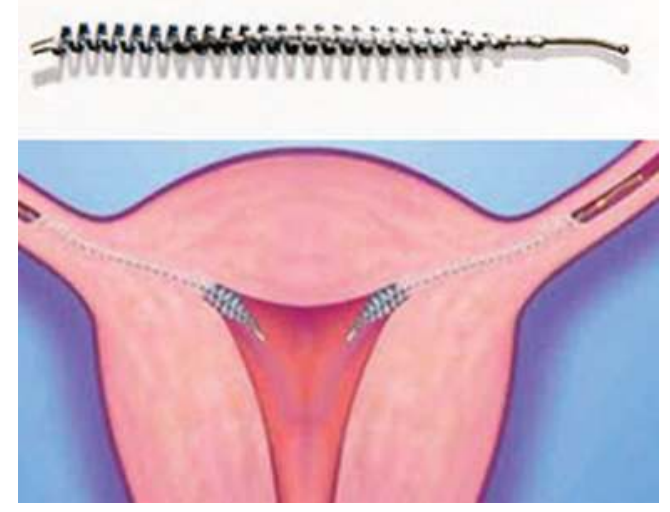

Figure 6. The Essure system and placement of the device.

pregnancy with Essure can be overcome by educating patients to respect the recommended instructions and comply to periodic follow-ups, including HSG protocol [98].

\section{Author details}

Iliescu Dominic Gabriel ${ }^{1}$, Ștefania Tudorache1, Simona Vlădăreanu², Nuți Daniela Oprescu Maria Cezara Mureșan ${ }^{4}$, Roxana Cristina Drăgușin ${ }^{1 *}$ and Iuliana Ceaușu ${ }^{5}$

*Address all correspondence to: roxy_dimieru@yahoo.com

1 Department of Obstetrics and Gynaecology, University of Medicine and Pharmacy, Craiova, Romania

2 Department of Obstetrics-Gynaecology and Neonatology, University of Medicine and Pharmacy "Carol Davila", Bucharest, Romania

3 Department of Obstetrics and Gynaecology, University of Medicine and Pharmacy "Carol Davila", Bucharest, Romania

4 Department of Obstetrics and Gynaecology, University of Medicine and Pharmacy “Victor Babeș", Timișoara, Romania

5 Department of Obstetrics and Gynaecology, University of Medicine and Pharmacy of Bucharest, Bucharest, Romania

\section{References}

[1] Winner B, Peipert JF, Zhao Q, Buckel C, Madden T, Allsworth JE, Secura GM. Effectiveness of long-acting reversible contraception. New England Journal of Medicine. 2012;366(21):1998-2007. PMID 22621627. DOI: 10.1056/NEJMoa1110855 
[2] Committee on Adolescent Health Care Long-Acting Reversible Contraception Working Group, The American College of Obstetricians and, Gynecologists. Committee opinion no. 539: adolescents and long-acting reversible contraception: implants and intrauterine devices. Obstetrics and gynecology. October 2012;120(4):983-988. PMID: 22996129. DOI: 10.1097/AOG.0b013e3182723b7d

[3] Guttmacher AF. Intra-uterine contraceptive devices. Journal of Reproduction and Fertility. 1965;10:115-128

[4] Richter R. Ein Mittel zur Verhueturng der Konzeption. Deutsche Medizinische Wochenschrift. 1909;35:1525-1527

[5] Margulies L. History of intrauterine devices, Bulletin of the New York Academy of Medicine. 1975 May;51(5):662-7

[6] Sivin I, Greenslade F, Schmidt F, Waldman SN. The Copper 380 Intrauterine Device: A Summary of Scientific Data. New York: Population Council, Inc; 1992. 1-50

[7] Hsia JK, Creinin MD. Intrauterine contraception. Seminars in Reproductive Medicine. 2016;34(3):175-182. DOI: 10.1055/s-0036-1571438

[8] Hubacher D. The checkered history and bright future of intrauterine contraception in the United States. Perspectives on Sexual and Reproductive Health. 2002 Mar-Apr;34(2):98-103

[9] Spinelli A, Talamanca IF, Lauria L. Patterns of contraceptive use in 5 European countries. American Journal of Public Health. 2000;90(9):1403-1408

[10] World Contraceptive Use 2012 (United Nations publication, POP/DB/CP/Rev2012); 2013 Update for the MDG Database: Contraceptive Prevalence (United Nations publication, POP/DB/CP/A/MDG2013); and 2013 Update for the MDG Database: UnmetNeed for Family Planning (United Nations publication, POP/DB/CP/B/MDG2013). Available http://www.un.org/en/development/desa/population/publications/pdf/family/ worldContraceptivePatternsWallChart2013

[11] Sutherland EG, Otterness C, Janowitz B. What happens to contraceptive use after injectables are introduced? An analysis of 13 countries.International Perspectives on Sexual and Reproductive Health. 2011;37:202-208

[12] Jo Dennis, MFFP, MRCGP, Career Grade Trainee, IUDs: Which device? The Journal of Family Planning and Reproductive Health Care 2002;28(2)

[13] Sivin I. Utility and drawbacks of continuous use of a copper T IUD for 20 years. Contraception. 2007;75(6, Suppl):S70-S75

[14] Cao X, Zhang W, Gao Y, et al. Immediate post-abortal insertion of the frameless GyneFix IUD: initial experience in China. British Journal of Family Planning. 2000;26:85-88

[15] http://www.eurogine.com

[16] Bayer Healthcare Pharmaceuticals Inc. Mirena Full Prescribing Information. 2014; Available at: http://labeling.bayerhealthcare.com/html/products/pi/Mirena_PI.pdf 
[17] Bayer Healthcare Pharmaceuticals Inc. Skyla Full Prescribing Information. 2013. Available at: http://labeling.bayerhealthcare.com/html/products/pi/Skyla_PI.pdf

[18] Eisenberg DL, Schreiber CA, Turok DK, Teal SB, Westhoff CL, Creinin MD, ACCESS IUS Investigators. Three-year efficacy and safety of a new 52-mg levonorgestrel-releasing intrauterine system. Contraception 2015;92(1):10-16

[19] Baram I, Weinstein A, Trussell J. The IUB, a newly invented IUD: a brief report. Contraception. 2014;89(2):139-141

[20] Reeves MF, Hathaway MJ, Canela Oleaga JM, Katz BH, Tal MG. A randomized singleblinded trial of VeraCept, a novel nitinol lowdose copper intrauterine contraceptive compared with a copper T380S intrauterine contraceptive [Abstract]. Obstetrics and Gynecology. 2015;125(5, Suppl):5s

[21] Ortiz ME, Croxatto HB, Bardin CW. Mechanisms of action of intrauterine devices. Obstetrical and Gynecological Survey. 1996;51(12 SUPPL)

[22] Achilles SL, Creinin MD, Stoner KA, Chen BA, Meyn L, Hillier SL. Changes in genital tract immune cell populations after initiation of intrauterine contraception. American Journal of Obstetrics and Gynecology. 2014;211(5):489

[23] Sonalkar S, Schreiber CA, Barnhart KT. Contraception. [Updated 2014 Nov 11]. In: De Groot LJ, Chrousos G, Dungan K, et al., editors. Endotext [Internet]. South Dartmouth (MA): MDText.com, Inc.; 2000. Available from: https://www.ncbi.nlm.nih.gov/books/NBK279148/

[24] ACOG. Practice bulletin 152: Emergency contraception. Obstetrics and Gynecology 2015;126(3):685-686

[25] Cleland K, Zhu H, Goldstuck N, Cheng L, Trussell J. The efficacy of intrauterine devices for emergency contraception: A systematic review of 35 years of experience. Human Reproduction. 2012;27(7):1994-2000

[26] Hubacher D, Reyes V, Lillo S, et al. Preventing copper intrauterine device removals due to side effects among first-time users: Randomized trial to study the effect of prophylactic ibuprofen. Human Reproduction. 2006;21(6):1467-1472

[27] Speroff L, Darney PD. Intrauterine Contraception. A Clinical Guide for Contraception. 5th ed. Philadelphia: Lippincott Williams \& Wilkins; 2011. pp. 239-280. ISBN: 978-160831-610-6

[28] Lewis RA, Taylor D, Natavio MF, Melamed A, Felix J, Mishell D Jr. Effects of the levonorgestrel-releasing intrauterine system on cervical mucus quality and sperm penetrability. Contraception 2010;82(6):491-496

[29] Croxatto HB, Ortiz ME, Valdez E. IUD mechanism of action. In: Bardin CW, Mishell DR Jr, eds. Proceedings from the Fourth International Conference on IUDs. London:Butterworth-Heinemann, 1994:44-62

[30] Bahamondes L, Valeria Bahamondes M, Monteiro I. Levonorgestrel-releasing intrauterine system: Uses and controversies. Expert Review of Medical Devices. 2008;5:437-445. PMID: 18573044. DOI: 10.1586/17434440.5.4.437 
[31] Hubacher D, Lara Ricalde R, Taylor DJ, Guerra Infante F, Guzman Rodriguez R. Use of intrauterine device and the risk of infertility among nulligravid women. New England Journal of Medicine. 2001;345:561-567

[32] Shelton JD. Risk of clinical pelvic inflammatory disease attributable to an intrauterine device. Lancet. 2001;257:443

[33] Zhao G, Li M, Zhu P, Xu R, Wang J, Xu R. A preliminary morphometric study on the endometrium from patients treated with indomethacin-releasing copper intrauterine device. Human Reproduction. 1997;12(7):1563-1566

[34] Tian K, Xie C, Xia X. Chitosan/alginate multilayer film for controlled release of IDM on $\mathrm{Cu} / \mathrm{LDPE}$ composite intrauterine devices. Colloids Surface B Biointerfaces. 2013;109:82-89

[35] Schulman L, Hess HM, Arias R, et al. Expert Roundtable. Intrauterine contraception: Patient and clinician considerations. OBG Management. 2009;July(Supplement):S1 8

[36] Trussell J. Contraceptive failure in the United States. Contraception. 2011;83(5):397-404

[37] Russo JA, Miller E, Gold MA. Myths and misconceptions about long-acting reversible contraception (LARC). Journal of Adolescent Health. 2013;52(4 Suppl):S14-S21

[38] Brockmeyer A, Kishen M, Webb A. Experience of IUD/IUS insertions and clinical performance in nulliparous women - a pilot study. The European Journal of Contraception \& Reproductive Health Care. 2008;13(3):248-254

[39] Mechanism of action, safety and efficacy of intrauterine devices. Report of a WHO Scientific Group. World Health Organ Tech Rep Ser. 1987;753:1-91

[40] Bednarek PH, Jensen JT. Safety, efficacy and patient acceptability of the contraceptive and non-contraceptive uses of the LNG-IUS. International Journal of Womens Health. 2010;1:45-58

[41] Kaislasuo J, Suhonen S, Gissler M, Lähteenmäki P, Heikinheimo O. Uterine perforation caused by intrauterine devices: Clinical course and treatment. Human Reproduction. 2013;28(6):1546-1551

[42] American College of Obstetricians and Gynecologists. ACOG Practice Bulletin No. 121: Long-acting reversible contraception: Implants and intrauterine devices. Obstetrics and Gynecology. 2011;118(1):184-196

[43] Paragard T 380 A. Intrauterine copper contraceptive [package insert]. Sellersville, Pa.; 2013. http://www.accessdata.fda.gov/drugsatfda_docs/label/2013/018680s066lbl.pdf. Accessed June 10, 2013

[44] U.S. Food and Drug Administration. Mirena (levonorgestrelreleasing intrauterine system) July 2008. Safety labeling changes approved by FDA Center for Drug Evaluation and Research (CDER). http://www.fda.gov/safety/medwatch/safetyinformation/safetyrelateddruglabelingchanges/ucm121936.htm. Accessed June 9, 2012

[45] Skyla (levonorgestrel-releasing intrauterine system) [package insert]. Wayne NJ: Bayer HealthCare Pharmaceuticals, Inc.; 2013. http://labeling.bayerhealthcare.com/html/products/pi/Skyla_PI.pdf. Accessed June 10, 2013 
[46] Hatcher RA, Trussell J, Nelson AL, Cates W Jr, Stewart FH, Kowal D. Contraceptive Technology. 19th rev ed. Ardent Media: New York (NY); 2007

[47] Trussell J. Contraceptive failure in the United States. Contraception. 2011;83(5):397-404

[48] Yoost J, Understanding benefits and addressing misperceptions and barriers to intrauterine device access among populations in the United States, Patient Prefer Adherence. 2014 Jul 3;8:947-57. DOI: 10.2147/PPA.S45710. eCollection 2014

[49] Centers for Disease Control and Prevention (CDC). US Medical Eligibility Criteria for Contraceptive Use, 2010. MMWR Recomm Rep. 2010;59(RR-4):1-86

[50] Cleland K, Raymond EG, Westley E, Trussell J. Emergency contraception review: Evidence-based recommendations for clinicians, Clinical Obstetrics and Gynecology. 2014 Dec;57(4):741-750

[51] Salma U, Xue M, Md Sayed AS, Xu D. Efficacy of intrauterine device in the treatment of intrauterine adhesions. Biomed Research International. 2014;2014:589296. DOI: $10.1155 / 2014 / 589296$

[52] Hubacher D, Grimes DA. Noncontraceptive health benefits of intrauterine devices: A systematic review. Obstetrics and Gynecology Survey. 2002;57(2):120-128

[53] Cameron IT. Randomised comparative trial of the levonorgestrel intrauterine system and norethisterone for treatment of idiopathic menorrhagia. British Journal of Obstetrics and Gynaecology. 1998;105(6):592-598

[54] Barrington JW, Bowen-Simpkins P. The levonorgestrel intrauterine system in the management of menorrhagia. British Journal of Obstetrics and Gynaecology. 1997;104(5):614-616

[55] Lindh I, Milsom I. The influence of intrauterine contraception on the prevalence and severity of dysmenorrhea: A longitudinal population study. Human Reproduction. 2013;28(7):1953-1960

[56] Vercellini P, Aimi G, Panazza S, De Giorgi O, Pesole A, Crosignani PG. A levonorgestrelreleasing intrauterine system for the treatment of dysmenorrhea associated with endometriosis: A pilot study. Fertility and Sterility. 1999;72(3):505-508

[57] Vercellini P, Frontino G, De Giorgi O, Aimi G, Zaina B, Crosignani PG. Comparison of a levonorgestrel-releasing intrauterine device versus expectant management after conservative surgery for symptomatic endometriosis: a pilot study. Fertility and Sterility. 2003;80(2):305-309

[58] Mueck AO, Seeger H, Rabe, Hormonal contraception and risk of endometrial cancer: A systematic review, Endocrine Related Cancer. 2010 Sep 23;17(4):R263-R271. DOI: 10.1677/ERC-10-0076

[59] Hubacher D. Intrauterine devices \& infection: Review of the literature. Indian Journal of Medical Research. 2014 Nov;140(Suppl):S53-S57

[60] MacIsaac L, Espey E. Intrauterine contraception: The pendulum swings back. Obstetrics and Gynecology Clinics of North America. 2007;34:91-111 
[61] Farley TM, Rosenberg MJ, Rowe PJ, Chen JH, Meirik O. Intrauterine devices and pelvic inflammatory disease: An international perspective. Lancet. 1992;339(8796):785-788

[62] Toivonen J, Luukkainen T, Allonen H. Protective effect of intrauterine release of levonorgestrel on pelvic infection: Three years ' comparative experience of levonorgestreland copper-releasing intrauterine devices. Obstetrics and Gynecology. 1991;77:261-264

[63] Walsh T, Grimes D, Frezieres R, et al. Randomised controlled trial of prophylactic antibiotics before insertion of intrauterine devices. IUD Study Group. Lancet. 1998;351:1005-1008

[64] Pap-Akeson M, Solheim F, Thorbert G, et al. Genital tract infections associated with the intrauterine contraceptive device can be reduced by inserting the threads into the uterine cavity. British Journal of Obstetrics and Gynaecology. 1992;99:676-679

[65] Sivin I. Dose- and age-dependent ectopic pregnancy risks with intrauterine contraception. Obstetrics and Gynecology. 1991;78(2):291-298

[66] Skjeldestad FE. How effectively do copper intrauterine devices prevent ectopic pregnancy? Acta Obstetricia et Gynecologica Scandinavica. 1997;76:684-690

[67] World Health Organization. Medical Eligibility Criteria for Contraceptive Use. 4th edn. Geneva: WHO. 2010. Accessed 12 April 2012 from: http://www.who.int/reproductive. health/publications/mec.pdf

[68] Stanwood NL, Bradley KA. Young pregnant women's knowledge of modern intrauterine devices. Obstetrics and Gynecology. 2006;108(6):1417-1422

[69] Kavanaugh ML, Frohwirth L, Jerman J, Popkin R, Ethier K. Long-acting reversible contraception for adolescents and young adults: Patient and provider perspectives. Journal of Pediatric \& Adolescent Gynecology. 2013;26(2):86-95

[70] Black K, Lotke P, Buhling KJ, Zite NB. Intrauterine contraception for Nulliparous women: Translating Research into Action (INTRA) group, A review of barriers and myths preventing the more widespread use of intrauterine contraception in nulliparous women. European Journal of Contraception \& Reproductive Health Care. 2012 Oct;17(5):340-350. DOI: 10.3109/13625187.2012.700744 Epub 2012 Jul 26

[71] Castellsague X, Diaz M, Vaccarella S, et al. Intrauterine device use, cervical infection with human papillomavirus, and risk of cervical cancer: A pooled analysis of 26 epidemiological studies. Lancet Oncology. 2011;12:1023-1031

[72] Koseoglu SB, Deveer R, Akin MN, Gurbuz AS, Kasap B, Guvey H. Is there any impact of copper intrauterine device on female sexual functioning? Journal of Clinical and Diagnostic Research. 2016 Oct;10(10):QC21-QC23

[73] IUDs - an update. Popul Rep B. 1995;6:1-35

[74] American College of Obstetricians and Gynecologists. The Intrauterine Device. ACOG technical bulletin no. 164. Washington, D.C: ACOG, 1992

[75] Bednarek PH, Jensen JT. Safety, efficacy and patient acceptability of the contraceptive and non-contraceptive uses of the LNG-IUS. International Journal of Womens Health. 2010;1:45-58 
[76] Dajani AS, Taubert KA, Wilson W, Bolger AF, Bayer A, Ferrieri P, et al. Prevention of bacterial endocarditis. Recommendations by the American Heart Association. Circulation 1997;96:358-66

[77] Sääv I, Aronsson A, Marions L, Stephansson O, Gemzell-Danielsson K. Cervical priming with sublingual misoprostol prior to insertion of an intrauterine device in nulliparous women: a randomized controlled trial. Human Reproduction. 2007;22(10):2647-2652

[78] Dijkhuizen K, Dekkers OM, Holleboom CA, et al. Vaginal misoprostol prior to insertion of an intrauterine device: an RCT. Human Reproduction. 2011;26(2):323-329

[79] Edelman AB, Schaefer E, Olson A, et al. Effects of prophylactic misoprostol administration prior to intrauterine device insertion in nulliparous women. Contraception. 2011;84(3):234-239

[80] Johnson BA. Insertion and removal of intrauterine devices. American Family Physician. 2005 Jan 1;71(1):95-102

[81] Nowitzki KM, Hoimes ML, Chen B, Zheng LZ, Kim YH. Ultrasonography of intrauterine devices. Ultrasonography. 2015 Jul;34(3):183-194

[82] Valsky DV, Cohen SM. The shadow of the intrauterine device. Journal of Ultrasound Medicine. 2006 May;25(5):613-616

[83] Drăguşin R-C, Florea M, Pătru CL, Iliescu DG, Cernea N, Tudorache S, Benefits of 3D ultrasound in the diagnosis of intrauterine device malposition. Obstetrica si Ginecologia. 2016;64

[84] Nadai MN, Martins WP, Ferriani RA, Vieira CS. Three-dimensional ultrasound imaging of an intrauterine device showing copper corrosion. Ultrasound in Obstetrics and Gynecology. 2013 Nov;42(5):606-607

[85] Peipert JF, Zhao Q, Allsworth JE, et al. Continuation and satisfaction of reversible contraception. Obstetrics and Gynecology. 2011;117(5):1105-1113

[86] Forrest JD. US women's perceptions of and attitudes about the IUD. Obstetrics and Gynecology Survey. 1996;51(12 Suppl):S30-S34

[87] Grunloh DS, Casner T, Secura GM, Peipert JF, Madden T. Characteristics associated with discontinuation of long-acting reversible contraception within the first 6 months of use. Obstetrics and Gynecology. 2013;122(6):1214-1221

[88] Nelson A, Apter D, Hauck B, et al. Two low-dose levonorgestrel intrauterine contraceptive systems: A randomized controlled trial. Obstetrics and Gynecology. 2013;122(6):1205-1213

[89] Teal SB, Sheeder J. IUD use in adolescent mothers: Retention, failure and reasons for discontinuation. Contraception. 2012;85:270-274

[90] Peipert J, Zhao Q, Allsworth J, et al. Continuation and satisfaction of reversible contraception. Obstetrics and Gynecology. 2011;117:1105-1113 
[91] Duffy S, Marsh F, Rogerson L, et al. Female sterilisation: A cohort controlled comparative study of ESSURE versus laparoscopic sterilisation. BJOG. 2005;112:1522-1528

[92] Dhanjal MK. Contraception in women with medical problems. Obstetric Medicine. 2008 Dec;1(2):78-87. DOI: 10.1258/om.2008.080014

[93] Sagili H, Divers M. Hysteroscopic sterilisation with Essure: A promising new alternative to tubal ligation? Journal of Family Planning and Reproductive Health Care. 2008 Apr;34 (2):99-102

[94] Sinha D, Kalathy V, Gupta JK, Clark TJ. The feasibility, success and patient satisfaction associated with outpatient hysteroscopic sterilisation. British Journal of Obstetrics and Gynaecology. 2007;114:676-683

[95] Kerin JF, Munday DN, Ritossa MG, Pesce A, Rosen D. Essure hysteroscopic sterilization: results based on utilizing a new coil catheter delivery system. Journal of American Association of Gynecologic Laparoscopists. 2004;11:388-393

[96] Agostini A, Bretelle F, Ronda I, Roger V, Cravello L, Blanc B. Risk of vasovagal syndrome during outpatient hysteroscopy. Journal of American Association of Gynecologic Laparoscopists. 2004;11:245-247

[97] Conceptus website. http://www.conceptus.com/ [Accessed 4 August 2007]

[98] Cooper JM, Carignan CS, Cher D, Kerin JF. Selective Tubal Occlusion Procedure 2000 Investigators Group. Microinsert nonincisional hysteroscopic sterilization. Obstetrics and Gynecology. 2003;102:59-67 
